\title{
A STUDY OF PATIENT'S SATISFACTION LEVEL WITH THEIR DENTAL APPEARANCE AND TREATMENT THEY DESIRE TO IMPROVE AESTHETICS AT SARDAR BEGUM DENTAL HOSPITAL PESHAWAR
}

\author{
Zainab Abdullah ${ }^{1}$, Nazir Ahmad² and Saira Afridi ${ }^{2}$ \\ 1. Private Practitioner \\ 2. Sardar Begum Dental College
}

\begin{abstract}
Objectives:

The purpose of this study was to evaluate the patient satisfaction level with their dental appearance and treatment they desired to improve their facial aesthetics.
\end{abstract}

\section{Material \& Methods:}

This cross-sectional study was performed out among 400 patients who visited the Sardar Begum Dental Hospital. A structured, interviewer-guided questionnaire was used to identify patient satisfaction level with their general dental appearance and desired treatments. Descriptive statistics such as mean and standard deviation (SD) for continuous variables and frequency and percentage for categorical variables were determined. The chi-square test was used to compare the age of patient's satisfaction level with their dental appearance. The level of significance was set at 0.05 .

\section{Results:}

Out of 400 patients, $39 \%$ were males and $60 \%$ were females. Mean age recoded was $25.05 \pm 10.02$ years. Of these patients, $64 \%$ were not satisfied with their general dental appearance. In addition, $\overline{59} \%$ were not happy with the color of their teeth, 51\% regarded their teeth as poorly aligned. Dissatisfaction with tooth color was significantly higher in female than in male patients. Tooth whitening was the treatment most desired by patients (45.2\%). 51\% females, as compared to males, considered their teeth to be more poorly aligned i.e. and was $51 \%$.

\section{Conclusions:}

Most patients in this study were not satisfied with their general dental appearance with a greater percentage of females expressing dissatisfaction than males. Age had an association with satisfaction level of the subjects. Unhappiness with tooth color and feelings of having protruding teeth also had a significant negative influence on patient satisfaction with general dental appearance.

\section{Key Words:}

Dental appearance, Satisfaction level, Desired treatment

\section{INTRODUCTION}

Physical appearance plays a key role in human social interaction and the teeth and smile are important features in determining the attractiveness of the face. Furthermore, the mouth is thought to be important in social interactions. Facial aesthetics seems to be a significant

\begin{tabular}{c}
\hline Correspondence: \\
Dr. Zainab Abdullah \\
Flat No.5, block 15D, G 11/4 PHA D type \\
apartments Islamabad. \\
Email: $\frac{\text { : r.xainab@gmail.com, }}{\text { Cell: 0320-9100311 }}$ \\
\hline
\end{tabular}
determinant of self and social perceptions. Facial appearance is not only seen as being more attractive but also more socially accepted by peers, teachers, employers, and others. Smiling is still considered to be one of the most effective methods of influencing people ${ }^{1}$.A key role in human social interactions is dental appearance which is essential in determining attractiveness of a face .

https://doi.org/10.37762/jgmds.2-1.60 
Tooth color, shape ,tooth shine, appearance of gums, alignment, proclination and retroclined teeth , dental caries in anterior teeth, non aesthetic fillings and fractures all are significant factors affecting appearance of teeth.

The appearance of the teeth is mostly influenced by gender, age and education level . Almost all the people desire to have pearly white teeth ${ }^{3 .}$ Satisfaction with dental appearance is always associated with whitening of teeth. Whitening is among the most popular cosmetic dental appearances because it can greatly improve how teeth look ${ }^{4}$ A whiter, brighter smile is one of the first things that people notice about your appearance. It's no mystery that whiter teeth make us look better, younger, more attractive and more confident. This is why men and women of all ages are now opting for teeth whitening systems to improve their smile. Apart from teeth whitening, correction of mal-aligned teeth is also nowadays considered as an ultimate treatment for desiring an effective dental appearance although malocclusion is a common disorder and its treatment vary from patient to patient depending on their requirements ${ }^{5}$. Psychological and social impacts influence one patient to have orthodontic treatment. Even orthodontic treatment sometimes is functional requirement for a patient to have efficient aesthetics. Esthetics has become as important as function, structure and biology, until about the last two decades in dental practice ${ }^{6}$ as current advertising and the media in general emphasize the effect of a pleasant appearance because of its importance in many everyday situations. 7 This fact leads to changes in patients' esthetic needs and consequence of dental treatment priority.

\section{OBJECTIVES}

The objectives of this study were:

1. To determine patient's satisfaction level regarding their dental appearance.

2. To determine treatment they desire to improve dental aesthetics.

\section{METHODOLOGY}

It was a cross sectional study conducted at outpatient department at Sardar Begum Dental College and Hospital, Peshawar. Institutional ethical approval and informed consent was taken from every patient. Using $95 \%$ confidence interval a Sample size of 400 subjects was calculated by who sample size calculator. Subjects were selected by non probability Convenience sampling. Subjects who were willing to participate, having upper and lower natural front teeth from $2^{\text {nd }}$ premolar of one side to $2^{\text {nd }}$ premolar of other side and of age group 15 to 40 years were included to participate.

Data was collected from patients through a structured questionnaire and was entered and analyzed using the statistical software SPSS version 20. Descriptive statistics such as mean and standard deviation (SD) for continuous variables and frequency and percentage for categorical variables were determined. The chi-square test was used to compare the sex, age of patients who with their dental appearance. The level of significance was set at 0.05 .

\section{RESULTS}

Out of 400 patients, $60 \%$ were female and $40 \%$ were male. Ages ranged from 15 to 40 years. Urban population was $26.2 \%$ and $73.8 \%$ of the people were from rural areas. $38 \%$ percent were married and $62 \%$ were unmarried. We found that $64 \%$ of these patients were not satisfied while $26 \%$ patients were satisfied with their general dental appearance and only $10 \%$ were neutral 
Table 1: Satisfaction level with General dental appearance

\begin{tabular}{|l|c|}
\hline SATISFACTION LEVEL & PERCENT \\
\hline SATISFIED & $26.0 \%$ \\
\hline NEUTRAL & $10.0 \%$ \\
\hline DISSATISFIED & $64.0 \%$ \\
\hline TOTAL & $\mathbf{1 0 0 . 0 \%}$ \\
\hline
\end{tabular}

$59.2 \%$ showed dissatisfaction with tooth color being the most common while satisfaction level with tooth color was found to be $25.8 \%$ and $15 \%$ were neutral (Table: 2)

Table 2: Satisfaction level with tooth color

\begin{tabular}{|l|c|}
\hline STISFATION LEVLE & PERCENT \\
\hline SATISFIED & $25.8 \%$ \\
\hline NEUTRAL & $15.0 \%$ \\
\hline DISSATISFIED & $59.2 \%$ \\
\hline TOTAL & $\mathbf{1 0 0 . 0 \%}$ \\
\hline
\end{tabular}

$57.2 \%$ subjects were satisfied with their gums appearance, $33.2 \%$ were dissatisfied and $9.2 \%$ were neutral with their gums appearance. In addition, some patients regarded their teeth as poorly aligned $51 \%$. Others reasons for dissatisfaction included self-reported presence of caries $43.4 \%$ and non-aesthetic restorations $18 \%$.Among major causes of dissatisfaction included malocclusion $47 \%$, discoloured teeth $41.5 \%$ and $11 \%$ non aesthetic fillings. About the treatments they desired to improve their appearance it was found that $45.25 \%$ wished to have their teeth whitened, followed by orthodontic treatment $36.75 \%$, restoration of tooth color $9.75 \%, 4.50 \%$ dental crowns $4.50 \%$ and other treatments $0.25 \%$.(Fig: 1 )

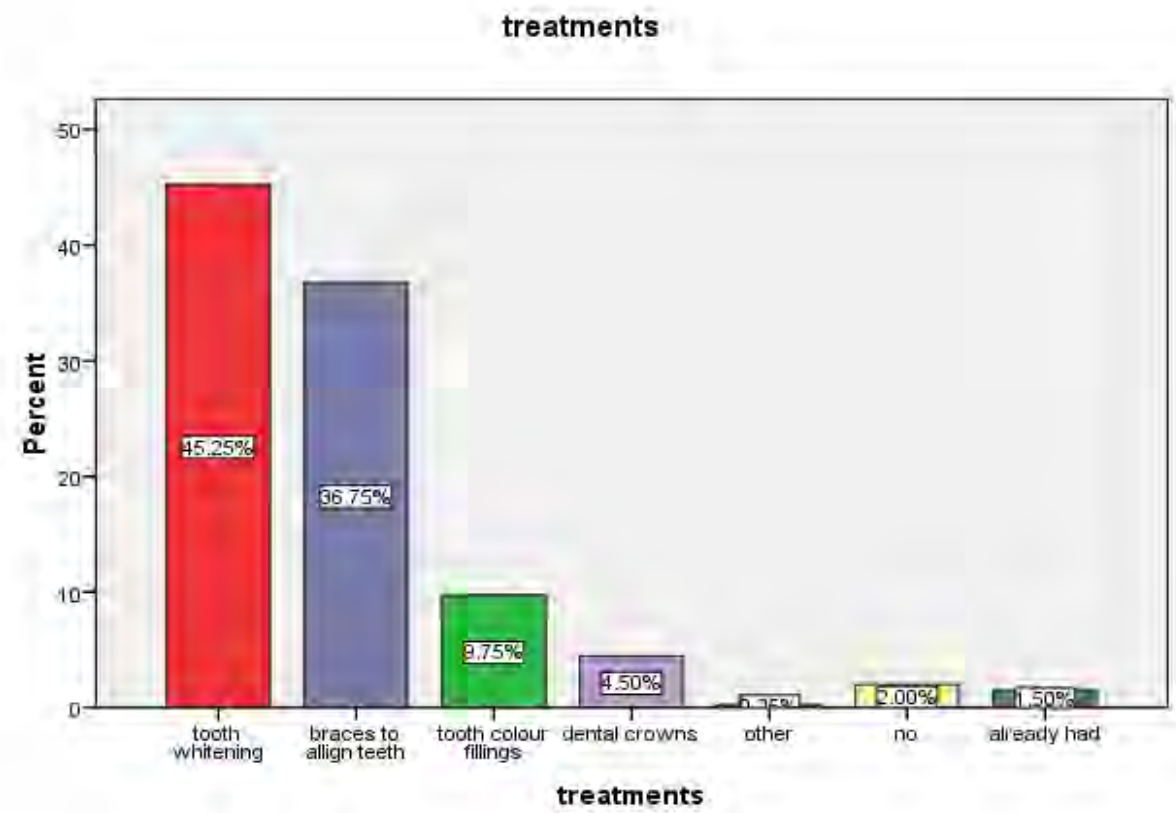

FIGURE 1: Treatments Desired To Improve Their Appearance 
It was $p$ value was found to be 0.007 which is highly significant showing that different age groups have different satisfaction level with their general dental appearance. Subjects of age 25-30 were highly dissatisfied with the general appearance. (Table: 4).

Table 4: Comparison of age and general dental appearance satisfaction level of patients

\begin{tabular}{|c|c|c|c|c|}
\hline Age & Satisfied & Neutral & Dissatisfied & P value \\
\hline $\mathbf{1 5 - 1 9}$ & 14 & 11 & 20 & .007 \\
\hline $\mathbf{2 0 - 2 4}$ & 27 & 11 & 54 & .007 \\
\hline $\mathbf{2 5 - 2 9}$ & 35 & 9 & 95 & .007 \\
\hline $\mathbf{3 0 - 3 4}$ & 17 & 2 & 72 & .007 \\
\hline $\mathbf{3 5 - 4 0}$ & 11 & 7 & 15 & .007 \\
\hline & 104 & 40 & 256 & \\
\hline
\end{tabular}

Test of Significance: Chi square value: 33.126

Level of significance: $p<0.05$. The chi square test was performed to find out the difference between age and general dental appearance, $P$ value.

\section{DISCUSSION}

The present study shows that majority of the patients visiting the dental OPD at Sardar Begum Dental College were dissatisfied with their general appearance. Gender had an impact on the general appearance of dental esthetics. From our study it is obvious that females were more dissatisfied with the general appearance of their tooth compared with males. The higher dissatisfaction level for females could be related to the idea that the self-esteems of females could be affected from physical injuries more than males. Vallittu et al., ${ }^{12}$ indicated similar results .The appearance of the teeth was found to be more important to women than to men. SamorodnitzkyNaveh et al., ${ }^{13}$ reported that females were more satisfied with the general appearance of their teeth from males in Israel. Age had an impact on dissatisfaction with dental esthetics. Adolescents and young adults with the age ranging from 25-30 were the most dissatisfied group, being the most dissatisfied with their dental appearance as also reported in a study in finland ${ }^{14}$ younger patients were more dissatisfied with dental appearance. Alkhatib et al., ${ }^{1}$ showed that older people were more satisfied with their dental appearance in the United Kingdom.

\section{CONCLUSIONS}

From this study it can be concluded that most patients are dissatisfied with their dental appearance. Dissatisfaction was more common in females than in males. Young ages were more dissatisfied with dental appearance. Dissatisfaction with tooth color and feelings of having protruding teeth also had significant negative influences on patient satisfaction with their general dental appearance. The importance of tooth color was further supported by our finding that most patients would like to have their teeth whitened followed by Orthodontics treatment.

\section{REFERENCES}

1. Alkhatib MN, Holt R, Bedi R. Age and perception of dental appearance and tooth colour. Gerodontology 2005;22:32-6

2. Al-Omiri M, Karasneh J, Lynch E, Lamey P, Clifford T.Impacts of missing upper anterior teeth on daily living. International Dental Journal 2009;3:127-32

3. Van der Geld P, Oosterveld P, Van Heck G, Kuijpers-Jagtman A.Smile attractiveness. Selfperception and influence on personality. The Angle Orthodontist2007;77:759-65 
4. Brisman AS. Esthetics. A comparison of dentists' and patients' concepts. J Am Dent Assoc 1980;100:345-52.

5. Odioso LL, Gibb RD, Gerlach RW. Impact of demographic, behavioral, and dental care utilization parameters on tooth color and personal satisfaction. Compend Contin Educ Dent Suppl 2000;29:35-41.

6. Joiner A.Tooth colour: a review of the literature. Journal of Dentistry2004;32:3-12

7. Höfel L, Lange M, Jacobsen T.Beauty and the teeth: perception of tooth color and its influence on the overall judgment of facial attractiveness. The International Journal of Periodontics \& Restorative Dentistry2007;27:349-57.

8. Akarslan Z, Sadik B, Erten H, Karabulut E. Dental esthetic satisfaction, received and desired dental treatments for improvement of esthetics. Indian Journal of Dental Research 2009;20:195-200.

9. Carlsson G, Johansson A, Johansson A, Ordell S, Ekbäck G, Unell L. Attitudes toward dental appearance in 50- and 60-Year-old subjects living in Sweden.Journal of Esthetic and Restorative Dentistry,2008; 20:46-55.

10. Mon tin-Oo, Norkhafizah Saddki, Nurhidayati Hassan. Factors influencing patient satisfaction with dental appearance and treatments they desire to improve aestheticsBMC Oral Health. 2011;11:6

11. Zhou YH, Hägg $U$, Rabie AB. Severity of dentofacial deformity, the motivations and the outcome of surgery in skeletal Class III patients. Chinese Medical Journal,2002; 115: 1031-1034.

12. Vallittu PK, Vallittu AS, Lassila VP. Dental aesthetics: A survey of attitudes in different groups of patients. J Dent 1996;24:335-8 .

13. Samorodnitzky-Naveh GR, Geiger SB, Levin L. Patients' satisfaction with dental esthetics. J Am Dent Assoc 2007;138:805-8.

14. Helm S, Petersen PE. Individual changes in malocclusion from adolescence to 35 years of age. Acta Odontologica Scandinavica1989; 47: 211-16.

LICENSE: JGMDS publishes its articles under a Creative Commons Attribution Non-Commercial Share-Alike license (CC-BY-NC-SA 4.0).
COPYRIGHTS: Authors retain the rights without any restrictions to freely download, print, share and disseminate the article for any lawful
purpose. It includes scholarly networks such as Research Gate, Google Scholar, LinkedIn, Academia.edu, Twitter, and other academic or
professional networking sites.

